\title{
E SPT PPh 21 Bagi Guru-Guru Sekolah Menengah Pertama Negeri 6 (SMP N) Siak Hulu
}

\author{
INOVA FITRI SIREGAR ${ }^{1}$; RINAYANTI RASYAD ${ }^{2}$; INDARTI ${ }^{3}$ \\ Universitas Lancang Kuning \\ Jln. Yos Sudarso KM 08 Rumbai Telp. (0761) 52581 \\ E-mail : siregar_inovafitri@yahoo.com
}

\begin{abstract}
Problems in by teachers the state junior high school 6 (junior high school) siak upstream is and his lack of access information and socialization even the low awareness of taxpayers for its liabilities perpajakannya still becomes an obstacle the low compliance taxpayers to pay off debt tax .Then misunderstanding teachers the state junior high school 6 (Junior high school) siak upstream in pengaplikasian reporting e like income tax 21 of the aspect of tax rates pengahasilan worn distinct by taxpayers, charging like that must be reported on income that they received, with the their reporting obligations, teachers prefer to use the consultants taxation without knowing reason of any pengahasilan they received cut any period of tax. Methods used is training and assistance in planning tax and bookkeeping.Success is measured using methods applied approach processes and products through method observation and interview held during and after training activities. The data collected is products for participants and training and extension in tax matter and bookkeeping.Training activities designed in three stages, consisting of the preparatory stage implementation and monitoring. The outcome of the activities devotion to the has done the great several components ketercapaian includes the target the total number of participants can be seen from the total number of participants the 30 people and is in fact attended by students 25 the activities so that the target the total number of participants had almost could be met.All the participants can take the process a simulation of beginning to done, activities designed 100 $\%$ done, readiness a team of teachers and the presence of $100 \%$.Delivery target matter also achieved because a matter can be delivered as a whole. So devotion to the objectives of the activities could be met.
\end{abstract}

Keywords: Training, Income Tax PPh 21

Pemerintah dalam hal ini Direktorat Jenderal Pajak seakan terus berburu pungutan masyarakat ini dengan berbagai upaya dan trik agar pajak akan terus menyandang primadonanya pendapatan negara di sektor non migas. Setiap waktu setiap saat melakukan perubahan dan mengeluarkan peraturan baru untuk mengisi pundi-pundi negara lewat pungutan pajak. Jargon terdahulu "orang bijak bayar pajak" dan berubah menjadi "bayarlah pajak awasi penggunannya" setelah banyak kasus mafia pajak bermunculan membuat mau tidak mau suka tidak suka masyarakat yang sudah berNPWP harus bayar pajak sebagai warga negara yang baik.

Di beberapa wilayah termasuk di Riau terdapat Direktorat Jenderal Pajak (DJP) sebagai kepanjangan tangan dari Kementerian Keuangan Republik Indonesia merupakan institusi pemerintah penghimpun pajak Negara. Selanjutnya DJP dibantu oleh instansi dibawahnya yang berdasarkan Peraturan Menteri Keuangan No. 132/PMK.01/2006

Tentang Organisasi dan Tata Kerja Instansi Vertikal Direktorat Jenderal Pajak, dibentuk Kantor Pelayanan Pajak (KPP) Pratama yang mempunyai tugas melaksanakan penyuluhan, pelayanan, dan pengawasan Wajib Pajak diantaranya adalah di bidang Pajak Penghasilan.

Pemerintah akan memulai upaya intensif menyadarkan setiap wajib pajak untuk membayar pajak, karena sebelumnya fokus penagihan pajak hanya pada pengusaha kena pajak. Kebijakan ini diharapkan akan menaikkan penerimaan pajak sekaligus memperluas basis 
penagihannya. Sulitnya menghitung pajak merupakan salah satu hal yang sering dikeluhkan masyarakat bila berhubungan dengan kantor pajak. Bukan hanya Wajib Pajak orang pribadi, Wajib Pajak badan juga mengalami hal yang sama.

Padahal bagi Wajib Pajak badan, ada kewajiban membuat laporan keuangan. Selain sebagai alat untuk mengetahui perkembangan usaha dan untuk kepentingan stakeholders, laporan keuangan juga sumber data untuk menghitung pajak. Dalam praktiknya sangat sering Wajib Pajak bertanya berapa pajak yang harus dibayar tanpa perlu mengetahui bagaimana proses penghitungannya. Asal sesuai dengan jumlah yang diinginkan, baru mau bayar pajak. Bila demikian halnya, tentu akan merusak sistem penghitungan pajak yang sudah terformulasi. Dan karena urusan pajak umumnya dianggap rumit oleh wajib pajak maka diperlukan adanya unit khusus pada Kantor Pelayanan Pajak yang melayani wajib pajak.

Proses penghitungan pajak tersebut yang akan menghasilkan jumlah pajak yang adil tanpa memberatkan Wajib Pajak namun sudah sesuai dengan ketentuan yang berlaku. Secara umum, formulasi menghitung pajak adalah dasar pengenaan pajak dikalikan tarif. Dasar pengenaan pajak untuk tiap jenis pajak berbeda satu sama lainnya. Untuk jenis Pajak Penghasilan $(\mathrm{PPh})$ disebut penghasilan kena pajak (PKP).

Permasalahan yang dialami oleh Guru-Guru Sekolah Menengah Pertama Negeri 6 (SMP N) Siak Hulu adalah Ketidaktahuan dan minimnya akses informasi dan sosialisasi bahkan rendahnya kesadaran Wajib Pajak atas kewajiban perpajakannya masih menjadi kendala rendahnya kepatuhan wajib pajak untuk membayar utang pajak.

Kemudian ketidakpahaman GuruGuru Sekolah Menengah Pertama Negeri 6 (SMP N) Siak Hulu dalam perhitungan dari aspek tarif pajak pengahasilan yang dikenakan berbeda oleh masing-masing wajib pajak, pengisian SPT yang wajib dilaporkan atas penghasilan yang mereka terima, dengan adanya kewajiban melapor tersebut, guru-guru lebih memilih untuk menggunakan jasa konsultan perpajakan tanpa mengetahui alasan dari setiap pengahasilan yang mereka terima dipotong setiap periode pajak.

Pada pengabdian sebelumnya tim pengabdian kepada masyarakat telah memberikan sosialisasi dan memberikan pemahaman mengenai bagaimana perhitungan pajak penghasilan orang pribadi, peserta pengabdian teridiri dari guru-guru smp n 6 siak hulu beserta dengan pegawai dan bendaharanya. Kemudian dari materi yang diajarkan kepada peserta, pihak sekolah sangat mengharapkan adanya sosialisasi lanjutan berupa bagaimana pemahaman untuk pengisian elektronik atas $\mathrm{PPh} 21$ berupa $\mathrm{E}$ filling dan selanjutnya bangaimana untuk melaporkan secara elektronik.

Sosialisasi ini juga didukung pada bulan Maret 2019 terakhir penyampaian dan pelaporan E Spt secara elektronik, pihak sekolah sangat kesusahan dalam penyampaian dan pelaporan secara elekronik, memang sampai saat ini pihak sekolah tidak pernah menyampaikan dan melaporkan pph 21 secara elektronik.

Berdasarkan uraian di atas, maka memberikan motivasi bagi kami dari dosen Fakultas Ekonomi Universitas Lancang Kuning untuk mengajukan usulan pengabdian kepada masyarakat.

Permasalahan yang dihadapi GuruGuru Sekolah Menengah Pertama Negeri 6 (SMP N) Siak Hulu terkait dengan kegiatan Pengabdian Kepada Masyarakat ini adalah : Keterbatasan SDM Guru-Guru Sekolah Menengah Pertama Negeri 6 (SMP N) Siak Hulu dari segi pendidikan maupun pengetahuan dan keterampilan dalam hal pengisian e spt pph 21 sehingga berpengaruh pada pelaporan setiap tahunnya; Terbatasnya sarana dan prasarana karena kurang informasi yang berhubungan dengan dalam hal pengisian e spt pph 21 bagi Guru-Guru Sekolah 
Menengah Pertama Negeri 6 (SMP N) Siak Hulu; Sesuai dengan penjelasan situasi yang dipaparkan pada pendahuluan dan analisis situasi, maka pada program pengabdian kepada masyarakat yang dapat dilakukan saat ini adalah melakukan E Spt PPh 21 Orang Pribadi Bagi Guru-Guru Sekolah Menengah Pertama Negeri 6 (SMP N) Siak Hulu. sebagai upaya untuk melaksanakan kewajiban perpajakan melalui langkah-langkah manajemen perpajakan yang baik. Langkah-langkah tersebut meliputi perencanaan pajak untuk mencapai pemenuhan kewajiban perpajakan.

\section{METODE}

Metode kegiatan dalam program pengabdian kepada masyarakat ini adalah pelatihan dan pendampingan Guru-Guru Sekolah Menengah Pertama Negeri 6 (SMP N) Siak Hulu dalam mengaplikasikan E SPT $\mathrm{PPh}$ 21. Dalam hal ini ketua program dan anggotanya berperan sebagai mediasi.

Metode Pelaksanaan Pengabdian Kepada Masyarakat. Pelaksanaan program pengabdian kepada masyarakat dilakukan dengan harapan yakni: Melakukan simulasi Guru-Guru Sekolah Menengah Pertama Negeri 6 (SMP N) Siak Hulu berdasarkan data yang ada yang dipandang memiliki kemampuan sumber daya manusia dan keuangan yang memenuhi syarat sesuai peraturan pajak (PP No. 46 Tahun 2013) atau dapat menjadi Wajib Pajak sesuai ketentuan KPP. Menginformasikan kegiatan kepada Guru-Guru Sekolah Menengah Pertama Negeri 6 (SMP N) Siak Hulu. Melakukan komunikasi intensif dengan para Guru-Guru Sekolah Menengah Pertama Negeri 6 (SMP N) Siak Hulu. Mencari tempat untuk dijadikan sebagai tempat pelatihan bagi para Guru-Guru Sekolah Menengah Pertama Negeri 6 (SMP N) Siak Hulu dalam kegiatan Pengabdian kepada Masyarakat. Membuat dan memberikan surat undangan kepada peserta sebelum kegiatan pengabdian masyarakat dilaksanakan.

Pelaksanaan kegiatan. Sesuai dengan dana yang tersedia, kegiatan ini direncanakan dilakukan satu kali dengan rencana kegiatan yang dilakukan adalah a) mengkaji kebijakan tentang PP No. 46 Tahun 2013 dan standar akuntansi bagi Guru-Guru Sekolah Menengah Pertama Negeri 6 (SMP N) Siak Hulu terkait pelaporan pajak dan E SPT PPh 21. b) mempertemukan pihak yang terlibat dalam penyuluhan dan pendampingan perencanaan pajak dan $\mathrm{E}$ SPT PPh 21dalam kegiatan Pengabdian kepada Masyarakat.

Evaluasi Keberhasilan. Hasil yang diterima dari kegiatan ini, dianalisis kembali oleh pelaksana kegiatan Pengabdian Kepada Masyarakat guna mengetahui tingkat keberhasilan kegiatan dan kekurangan dan hal-hal yang harus dilakukan lagi agar tujuan kegiatan dapat terlaksana dengan baik dan memberi manfaat praktis kepada semua pihak yang terlibat dalam pelatihan perencanaan pajak bagi Guru-Guru Sekolah Menengah Pertama Negeri 6 (SMP N) Siak Hulu

\section{HASIL}

Pengabdian Kepada Masyarakat ini dilakukan oleh Bagi Guru SMP N 6 Siak Hulu. Acara bertempat di Ruangan Guru SMP N 6 Siak Hulu dengan judul "E SPT Pajak Penghasilan Pasal 21 bagi Guru Guru SMP N 6 Siak Hulu”. Sebelum kegiatan penyampaian materi mengenai pajak penghasilan dan bagaimana menghitung pajak penghasilan pasal 21,tim dosen memberikan kuesioner untuk mengukur tingkat pemahaman mengenai materi dan cara menggunakan aplikasi E Filling yang akan diberikan pada saat pengabdian ini. Pada kegiatan pembekalan ini peserta sangat antusias mengikuti materi pembekalan terutama untuk materi E SPT pajak penghasilan pasal 21 yang diarahkan kepada perhitungan masing-masing penghasilan guru. Jumlah Pertanyaan yang diberikan kepada guru sebanyak 10 pertanyaan 
Tabel 1: Hasil Rekapitulasi Kuesioner Pengabdian Kepada Masyarakat

\begin{tabular}{|l|l|l|l|}
\hline No & Keterangan & PreTest & PostTest \\
\hline 1 & $\begin{array}{l}\text { Apakah anda memahami apa } \\
\text { yang dimaksud dengan pajak } \\
\text { penghasilan? }\end{array}$ & $10 \%$ & $80 \%$ \\
\hline 2 & $\begin{array}{l}\text { Apakah E Fin Penting dalam } \\
\text { melaporkan E SPT? }\end{array}$ & $10 \%$ & $100 \%$ \\
\hline 3 & $\begin{array}{l}\text { Apakah anda mempunyai No } \\
\text { NPWP? }\end{array}$ & $10 \%$ & $100 \%$ \\
\hline 4 & $\begin{array}{l}\text { Apakah daftar harta ada } \\
\text { dalam kolom E SPT? }\end{array}$ & $0 \%$ & $90 \%$ \\
\hline 5 & $\begin{array}{l}\text { Apakah E spt pph 21 hanya } \\
\text { untuk menginput pegawai } \\
\text { tetap saja? }\end{array}$ & $0 \%$ & $90 \%$ \\
\hline 6 & $\begin{array}{l}\text { Apakah SSP harus diinput } \\
\text { dan dilampirkan dalam E } \\
\text { SPT? }\end{array}$ & $0 \%$ & $100 \%$ \\
\hline 7 & $\begin{array}{l}\text { Apakah laporan SPT induk } \\
\text { dapat di cetak pada E SPT } \\
\text { PPh 21? }\end{array}$ & $0 \%$ & $80 \%$ \\
\hline 8 & $\begin{array}{l}\text { Apakah No SSP dilampirkan? } \\
\text { Apakah E SPT PPh 21 } \\
\text { digunakan untuk menginput } \\
\text { data pajak pertambahan nilai? }\end{array}$ & $0 \%$ & $80 \%$ \\
\hline 10 & $\begin{array}{l}\text { Apakah Pelatihan Pengisian } \\
\text { E SPT sangat penting? }\end{array}$ & $60 \%$ & $100 \%$ \\
\hline
\end{tabular}

$\begin{array}{rrrr}\text { Kesulitan } & \text { yang paling } & \text { mendasar } \\ \text { dialami } & \text { oleh } & \text { Guru-Guru } & \text { adalah }\end{array}$ ketidaktahuan dan tidak memahami atas bearapa banyak potongan pajak atas penghasilan apapun yang mereka terima dari pertama kali mengajar hingga pada saat ini.dan bagaimana membayarkan hingga malaporkan SPT yang telah dibuat. Hal ini disebabkan oleh mereka tidak pernah mendapatkan sosialisasi dan pelatihan meneganai bagaimana perhitungan pajak penghasilan hingga pengisian dan pelaporan E SPT PPh 21

Ketika kegiatan pengabdian kepada masyarakat dilaksanakan pada tanggal 29 Juni 2019, jumlah Guru yang hadir sebanyak 25 orang. Pada kegiatan ini, tim dosen memberikan materi dasar (konsep) pajak penghasilan, bagaimana wajib pajak harus membayarkan pajak atas penghasilannya, jumlah besaran penghasilan tidak kena pajak (PTKP) hingga tariff yang dikenakan pada Pph 21 hingga pengisian dan pelaporan E SPT PPh 21, setelah tim dosen memberikan materi konsep dasar pph 21 , tim memberikan contoh kasus perhitungan Pph 21 dan memberikan simulasi kepada setiap guru -guru atas penghasilan yang mereka peroleh setiap bulannya.

\section{PEMBAHASAN}

Hasil kegiatan pengabdian pada masyarakat yang telah dilakukan secara garis besar mencakup beberapa komponen, yaitu keberhasilan target jumlah peserta pelatihan, ketercapaian target materi yang telah direncanakan, ketercapaian tujuan pelatihan dan kemampuan peserta dalam penguasaan materi. Ketercapaian target jumlah peserta dapat dilihat dari jumlah peserta yang ditargetkan adalah 30 orang dan pada kenyataannya kegiatan diikuti sebanyak 25 orang sehingga target jumlah peserta hampir telah dapat terpenuhi. Semua peserta dapat mengikuti seluruh proses simulasi dari awal sampai selesai, kegiatan yang dirancang 100\% terlaksana, dan kehadiran kesiapan tim Guru $100 \%$. Target penyampaian materi simulasi juga tercapai karena materi dapat disampaikan secara keseluruhan. Dengan demikian maka tujuan kegiatan Pengabdian Kepada Masyarakat dapat terpenuhi.

Kegiatan menulis khususnya perhitungan pajak penghasilan pasal 21 bukanlah pekerjaan yang mudah. Untuk dapat menghasilkan pemahaman yang baik, diperlukan latihan yang banyak. Kemampuan menghitung dan memahami ini tidak dapat diperoleh dalam waktu singkat. Latihan ini memerlukan ketekunan dan kebiasaan. Keterampilan menulis adalah keterampilan yang tidak dibawa sejak lahir, tetapi keterampilan ini dapat dipelajari dan diajarkan. Berdasarkan evaluasi pelaksanaan kegiatan dapat diidentifikasi faktor pendukung dalam pelaksanaan program pengabdian kepada masyarakat adalah : Adanya kerjasama yang baik antara tim pengabdian kepada masyarakat dengan peserta pengabdian kepada masyarakat yaitu pada Guru di SMP N 6 Siak Hulu.

Adanya kerjasama yang baik antara tim pengabdian kepada masyarakat dengan pada Guru Guru di SMP N 6 Siak Hulu beserta jajarannya dalam mensupport terselenggaranya kegiatan ini dalam bentuk 
pemberian fasilitas ruangan, proyektor, menghadirkan para Guru yang akan diberikan sosialisasi atau pelatihan tentang penulisan jurnal ilmiah bagi Guru dan memberikan kata sambutan sekaligus membuka kegiatan pengabdian kepada masyarakat tersebut.

\section{SIMPULAN}

Kegiatan pengabdian kepada masyarakat ini dilaksanakan di Ruangan Guru Guru di SMP N 6 Siak Hulu dengan judul "Pajak Penghasilan Pasal 21 Bagi Guru-Guru SMP N 6 Siak Hulu " yang diadakan pada hari Senin, 29 Juni 2019 yang dihadiri oleh 25 Peserta, terdiri dari GuruGuru Guru di SMP N 6 Siak Hulu Sesuai dengan tujuan kegiatan pengabdian kepada masyarakat yang telah dilakukan, dapat diambil beberapa kesimpulan sebagai berikut: Meningkatkan peran serta bagi Guru Guru SMP N 6 Siak Hulu dalam ikut membantu memberikan pemahaman mengenai perhitungan pajak penghasilan pasal 21 sehingga dapat bersaing dengan dilaksanakan kegiatan pengabdian kepada masyarakat dalam bentuk sosialisasi.

Pada pelaksanaan sosialisasi, peserta diberikan pemahaman dan pelatihan mengenai perhitungan pajak penghasilan pasal 21. Dengan hasil para peserta pengabdian kepada masyarakat sangat antusias. Bentuk antusisme peserta adalah banyaknya para peserta PKM yang memberikan pertanyaan dan sharing pengetahuan berkenaan dengan Pajak Penghasilan.

Berdasarkan kesimpulan di atas, maka dapat kami sarankan hal-hal sebagai berikut : Guru (Pesrta) hendaknya meningkatkan kualitas pemahamannya dengan meningkatkan frekuensi latihan atau menghitung sendiri pajak penghasilan yang dipotong setiap tahunnya. Dengan cara itu, kualitas pemahaman dapat ditingkatkan. Selain, itu, para bagi Guru Guru SMP N 6 Siak Hulu hendaknya tidak hanya perhitungan pajak penghasilan pasal 21 secara manual atau perhitungan excel (komputerisasi) tetapi meningkatkan pemahaman bagaimana menggunakan aplikasi E SPT untuk menghitung PPh 21.

\section{DAFTAR RUJUKAN}

Fitriandi, Primandita. 2006. USKP Review - Ujian Sertifikasi Konsultan Pajak. Jakarta: Salemba Empat.

Kantor Pelayanan Pajak. 2007. Formulir SPT Tahunan PPh Wajib Pajak Orang ribadi (SPT 1170 beserta lampiran-lampirannya). www.pajak.go.id

Mardiasmo. 2006. Perpajakan. Yogyakarta: Andi Offset.

Siti Resmi. 2016. Perpajakan Edisi 2. Jakarta: Salemba Empat.

Azhar Mohamad, Neazlin Radzuan, Zarinah Hamid, Journal of Financial Crime

Tax Arrears Amongst Individual Income Taxpayers In Malaysia

http://www.emeraldinsight.com/doi/pdfplus $\underline{\text { /10.1108/JFC-10-2015-0055 }}$

Antonio Martin, An ssessment Of Recent Trends On Income Taxation And Environmental Policy In Portugal. http://www.emeraldinsight.com/do i/pdfplus/10.1108/1477783111113 $\underline{6036}$

Don Bruce, Jon C. Rork, Gary Wagner. Journal of Entrepreneurship and Public Policy

State income tax reciprocity agreements and small businesses. http://www.emeraldinsight.com/do i/pdfplus/10.1108/JEPP-07-2012$\underline{0037}$ 
Fadi, Martin and Roberto. The Determinants of Tax Morale and Tax Compliance: Evidence from Jordan. Book Series: Advances in Taxation. Series ISSN: 1058-7497

http://www.emeraldinsight.com/doi/ pdfplus/10.1108/S1058$\underline{749720160000023005}$

Ferguson. Personal Income taxation: An Evaluation Of The Argument For A Personal Expenditure Tax Studies in Economics and Finance ISSN: 1086-7376 Online from: 1977. http://www.emeraldinsight.com/doi/ pdfplus/10.1108/eb028623

Hendri. David, James . Tax Compliance Intentions of Low-Income Individual Taxpayers http://www.emeraldinsight.com/doi/ pdfplus/10.1016/S14751488\%2804\%2907001-2

John Creedy. Income taxation and the accounting period: A simulation analysis. Journal of Economic Studie.

http://www.emeraldinsight.com/doi/ pdfplus/10.1108/014435898102338 $\underline{56}$

Rebekah. Corporate Income Tax Systems and State Economic Activity Book Series: Advances in Taxation. Series ISSN: $\quad$ 1058-7497. http://www.emeraldinsight.com/doi/ pdfplus/10.1108/S1058749720140000021004 